\title{
Gallium-67 Scanning in Patients with Malignant Pleural Mesothelioma
}

\author{
Takashi NAKANO, Juichiro MAEDA, Noriaki IWAHASHI, \\ Shinsuke TAMURA, Toshikazu HADA and Kazuya HigASHINO
}

\begin{abstract}
The findings of Gallium-67 scans in eleven patients with malignant pleural mesothelioma were reviewed and compared to those of chest CT findings. All patients had an abnormal thoracic Ga-67 accumulation. Six out of 11 showed a diffuse accumulation over the entire involved hemithorax and a localized uptake was shown in 5. A marked diffuse thickening of pleura in the absence of adequate gallium accumulation was observed in one patient. Two out of 11 had a reduction of gallium uptake after having combination chemotherapy. These results suggest that a diffusely increased uptake over the entire involved hemithorax is the most characteristic finding of Ga-67 scan in malignant pleural mesothelioma, and that Ga-67 scans may be helpful as a valuable indicator of the proper therapy. However, the superiority of Ga-67 scan to thoracic CT as a means of determining the extent of disease process could not be verified.
\end{abstract}

Key words: Gallium-67 scans, CT scan, Pleural thickening, Chemotherapy

Gallium-67 (Ga-67) citrate was first advocated for tumor imaging in 1969 by Edwards and Hayes (1, 2). Subsequently, Ga-67 scanning became a widely and routinely used method of defining the extent of inflammatory and tumoral diseases. Positive Ga-67 scanning has indicated the existence of various pulmonary diseases. Malignant pleural mesothelioma is a rare thoracic neoplasm the incidence of which is rising with the increasing use of asbestos in industry. Chest X-ray and computed tomography (CT) findings of this neoplasm are well described, however, there are only limited case reports of the findings of Ga-67 scans (3-6). The accumulation of Ga-67 in malignant pleural mesothelioma may occur at the site of the involved pleura. Therefore, the gallium distribution may be proportionate to the radiographic extent of the tumor.

In this report, we describe the findings of Ga-67 scans in patients with malignant pleural mesothelioma, and the findings of Ga-67 scans are compared with those of chest CT.

\section{MATERIAL AND METHODS}

Eleven patients with malignant pleural mesothelioma, who were seen at the Third Department of Internal Medicine, Hyogo College Hospital from 1980 to 1989 , were studied. The diagnosis of malignant pleural mesothelioma was made on the basis of histologic and histochemical studies of pleural biopsy specimens and by the cytologic examination of the pleural fluids. The diagnosis was supported by our previously reported biochemical studies on glycosaminoglycan in the tumor tissue, which showed a marked increase in the total amount of this substance (7).

A Ga-67 scan was performed 72 hours after intravenous injection of $2.5 \mathrm{mCi}$ of $\mathrm{Ga}-67$ citrate. A Shimazu scintillation scanner was used. The Ga-67 scans and CT findings were determined independently by two investigators who had no

From The Third Department of Internal Medicine, Hyogo College of Medicine, Nishinomiya

Received for publication August 24, 1989; Accepted for publication April 25, 1990

Reprint requests should be addressed to Takashi Nakano, MD, The Third Department of Internal Medicine,

Hyogo College of Medicine, 1-1 Mukogawa-cho, Nishinomiya 663, Japan 
knowledge of the clinical state of the patient and then were compared. The CT of the chest was performed within 10 days of the Ga-67 scan. Thickness of pleura was expressed as the mean pleural thickness measured by chest CT.

\section{RESULTS AND DISCUSSION}

Twenty-four Ga-67 scans were performed on 11 patients with malignant pleural mesothelioma. The results of Ga-67 scans and chest $\mathrm{CT}$ before chemotherapy are summarized in Table 1 .
All patients had an abnormal thoracic gallium accumulation. Pleural mesothelioma may spread directly along the pleural surface and the tumor frequently encases the entire lung. In our findings, CT of the chest showed a diffuse pleural thickening surrounding the whole lung surface and mediastinum in 9 out of 11 mesotheliomas. Of the nine patients who showed a diffuse pleural thickening on CT, six showed a diffuse hemithoracic uptake of Ga-67 over the entire involved hemithorax (Fig. 1 mixed type, Fig. 2, Fig. 3 epithelial type). This gallium uptake

Table 1. Results of gallium-67 scanning and thoracic CT before chemotherapy in eleven patients with malignant pleural mesothelioma.

\begin{tabular}{lllll}
\hline & \multicolumn{3}{c}{ Findings of thoracic CT } \\
\cline { 2 - 5 } $\begin{array}{l}\text { Gallium-67 } \\
\text { image }\end{array}$ & $\begin{array}{l}\text { Diffuse pleural } \\
\text { thickening }\end{array}$ & $\begin{array}{l}\text { Pleura-based mass } \\
\text { with pleural } \\
\text { thickening }\end{array}$ & $\begin{array}{l}\text { Involvement of } \\
\text { interlobar } \\
\text { fissure }\end{array}$ & $\begin{array}{l}\text { Pleural } \\
\text { effusion }\end{array}$ \\
\hline $\begin{array}{l}\text { Diffuse accumulation } \\
\text { over the entire }\end{array}$ & $6 / 6(100 \%)$ & 0 & $3 / 6(50 \%)$ & $6 / 6(100 \%)$ \\
$\begin{array}{l}\text { involved hemithorax } \\
\text { (n=6) }\end{array}$ & & & & \\
\hline & & & & \\
Localized & & & & \\
accumulation & & & & \\
(n=5) & $3 / 5(60 \%)$ & $\begin{array}{l}7.5 \mathrm{~cm} \times 7.5 \mathrm{~cm} \S \\
6.0 \mathrm{~cm} \times 7.0 \mathrm{~cm} \S \\
5.0 \mathrm{~cm} \times 7.5 \mathrm{~cm} \S \\
1.5 \mathrm{~cm} \times 3.5 \mathrm{~cm}\end{array}$ & $1 / 5(20 \%)$ & $5 / 5(100 \%)$ \\
\hline
\end{tabular}

$\S$ positive gallium-67 scanning, I negative gallium-67 scanning
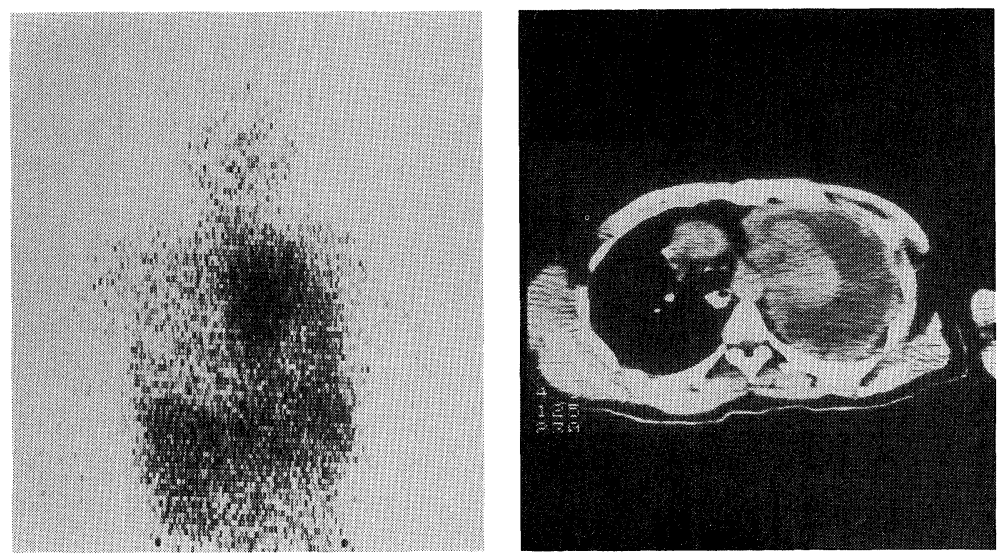

Fig. 1. Left; Anterior view of a Ga-67 scan in a patient with the mixed type of malignant pleural mesothelioma showing diffuse strong accumulation over the involved hemithorax. Right; Thoracic CT of the same patient showing diffuse pleural thickening along the inner thoracic wall and pleural effusion. 

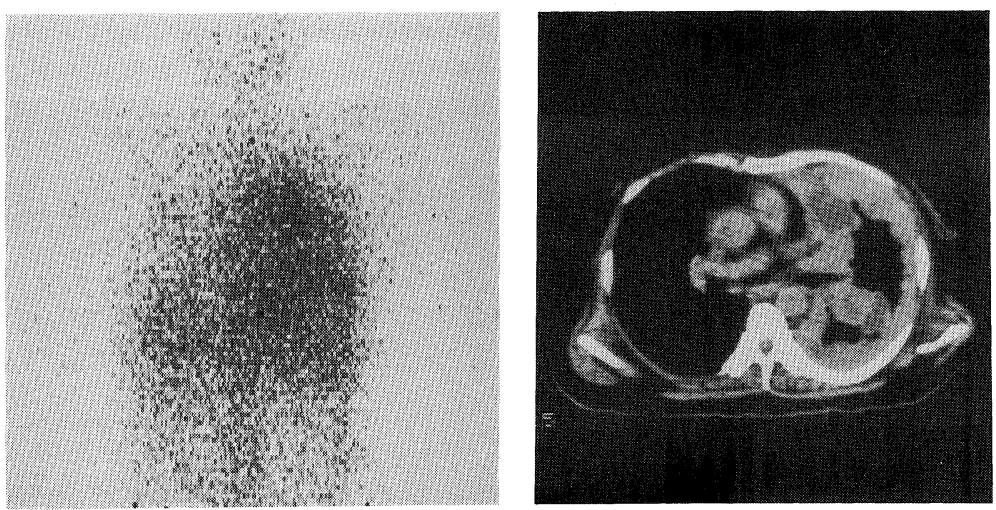

Fig. 2. Left; Anterior view of a Ga-67 scan in a patient with the epithelial type of malignant pleural mesothelioma showing diffuse strong accumulation. Right; Thoracic CT showing marked pleural thickening surrounding the whole lung surface and involvement of inter lobarfissure.
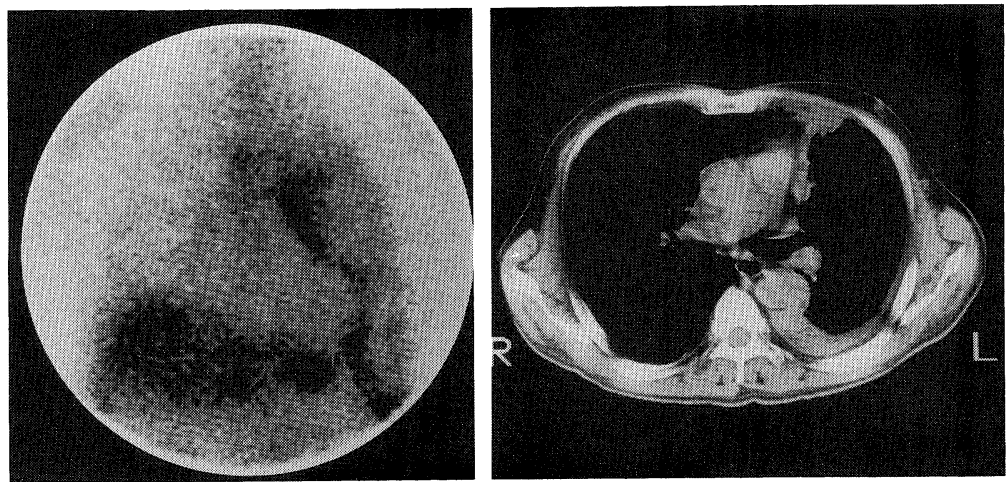

Fig. 3. Left; Anterior view of a Ga-67 scan in a patient with the epithelial type of malignant pleural mesothelioma showing diffuse accumulation over the involved hemithorax, with particular strong activity at the apex, mediastinum, and base. Right; Thoracic CT showing diffuse pleural thickening.

pattern may be one of the most characteristic findings of Ga-67 scans in malignant pleural mesothelioma, and may support thoracic CT findings.

Table 2 shows the results of Ga-67 scans before chemotherapy according to the mean pleural thickness surrounding the whole lung surface. Three out of 4 patients with a pleural thickness of over $10 \mathrm{~mm}$ showed a diffuse strong Ga-67 accumulation over the involved hemithorax. On the other hand, a pleural thickness of less than $10 \mathrm{~mm}$ showed a diffuse slight accumulation in two patients, but localized accumulation in the remaining three.
Interestingly, in one out of the 11 mesotheliomas showing a marked pleural thickening on the chest CT there was no adequate concentration of Ga-67 citrate (Fig. 4). This discrepancy between radiographic abnormalities and gallium accumulation might be due to a difference in tumor avidity for Ga-67 citrate in individual mesotheliomas. It has been reported that malignant mesotheliomas present one of three pathologic subtypes; epithelial, sarcomatous, or mixture of the two (8). There might be some relationship between the morphologic features and gallium activity. However, in our results, no histologic correlation to gallium avidity could be 
Table 2. Findings of gallium-67 scanning before chemotherapy according to the thickness of the involved pleura surrounding the whole lung surface in malignant pleural mesothelioma.

\begin{tabular}{|c|c|c|c|}
\hline \multirow{2}{*}{$\begin{array}{l}\text { *Thickness } \\
\text { of pleura }\end{array}$} & \multicolumn{2}{|c|}{ Gallium-67 scanning findings } & \multirow[b]{2}{*}{$\begin{array}{l}\text { Localized } \\
\text { accumulation }\end{array}$} \\
\hline & $\begin{array}{l}\dagger \text { Diffuse strong accumulation } \\
\text { over the involved hemithorax }\end{array}$ & $\begin{array}{l}\S \text { Diffuse slight accumulation } \\
\text { over the involved hemithorax }\end{array}$ & \\
\hline $\begin{array}{l}<10 \mathrm{~mm} \\
(\mathrm{n}=5)\end{array}$ & 0 & $2 / 5(40 \%)$ & $3 / 5(60 \%)$ \\
\hline $\begin{array}{l}\geqq 10 \mathrm{~mm} \\
(\mathrm{n}=4)\end{array}$ & $3 / 4(75 \%)$ & $1 / 4(25 \%)$ & 0 \\
\hline
\end{tabular}

*Thickness of pleura is expressed as the mean pleural thickness surrounding the whole lung surface measured by thoracic CT scan.

$\dagger$ gallium-67 concentration equal to or exceeding hepatic gallium concentration.

$\S$ gallium-67 concentration higher than body background, but less than hepatic gallium concentration.
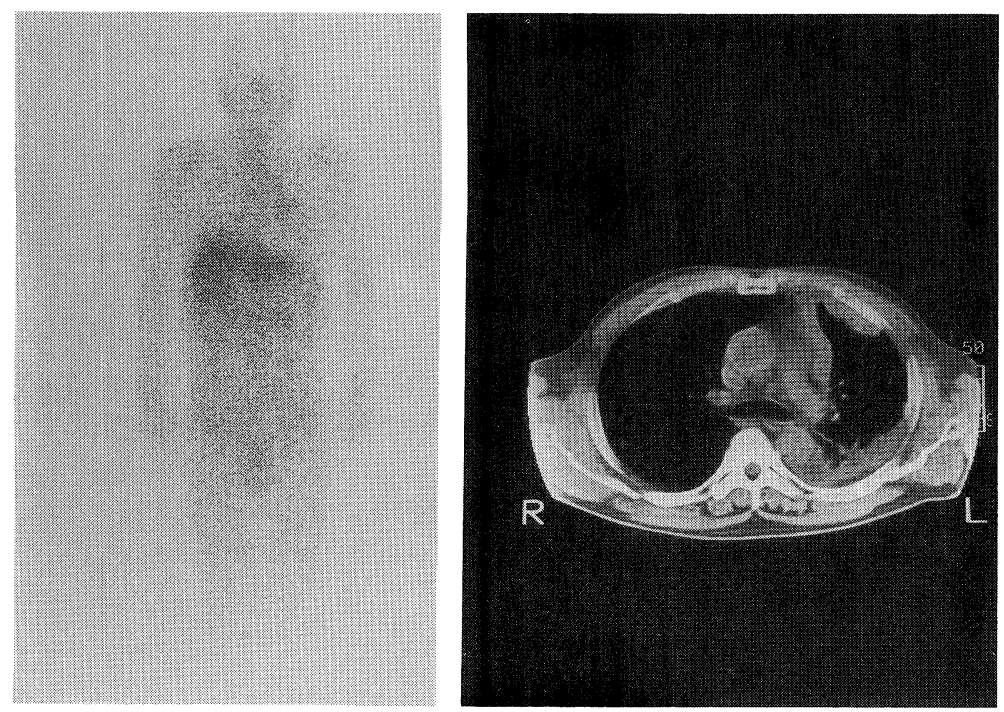

Fig. 4. Left; Anterior view of a Ga-67 scan in a patient with the epithelial type of malignant pleural mesothelioma showing diffuse slight accumulation. Right; However, thoracic CT of the patient shows marked pleural thickening surrounding the whole lung surface.

Note that in this patient there is no adequate concentration of Ga-67 citrate.

found.

The detectability of Ga-67 scanning of the pleurabased mass was evaluated according to the size of the mass measured by chest CT (Table 1). In one patient, the anterior view of Ga-67 scanning showed a localized accumulation in the left upper lung field
(Fig. 5a, 5b), which corresponded to a pleural mass, $8.5 \times 7.0 \mathrm{~cm}$ in diameter, seen on the chest CT. However, in another patient, CT revealed a pleurabased mass, $1.5 \times 3.5 \mathrm{~cm}$ in diameter, which was not identified by Ga-67 scans. In bronchogenic carcinoma, Bekerman et al have reported that $75 \%$ 
of patients with lesions between 1.5 and $3.0 \mathrm{~cm}$ in diameter had positive gallium scans, and the size limits for gallium detectability appear to be between 1 to $2 \mathrm{~cm}$ in diameter (9). In the present results, Ga-67 scanning had a sensitivity for pleura-localized lesions of $5.0 \times 7.5 \mathrm{~cm}$ in diameter or larger. However, the number of samples $(n=11)$ was so small, that we could not determine the precise threshold size of pleural mass for detection by Ga-67 scanning in malignant pleural mesothelioma.

It has been reported that decreased or complete suppression of Ga-67 uptake in lung cancer occurs after treatment $(10,11)$. In our results, two out of 11 mesotheliomas (18.2\%) that were initially Ga-67 abnormal positive had a reduction of gallium uptake after 2 cycles of combination chemotherapy with cyclophosphamide $1000 \mathrm{mg} / \mathrm{m}^{2}$, vincristine 1 $\mathrm{mg} / \mathrm{m}^{2}$, and aclacinomycin $40 \mathrm{mg} / \mathrm{m}^{2}$ by intravenous injection (Fig. 6). However, there was no reduction in the size of the pleural tumor seen in the chest CT taken after chemotherapy. The remaining mesotheliomas had persistently positive $\mathrm{Ga}-67$ scans while being treated. Ga-67 scans may be beneficial as a valuable indicator of the effectiveness of the ongoing chemotherapy.

Malignant pleural mesothelioma is a gallium avid tumor, and the gallium uptake pattern corresponds to the radiographic findings, however, there is not

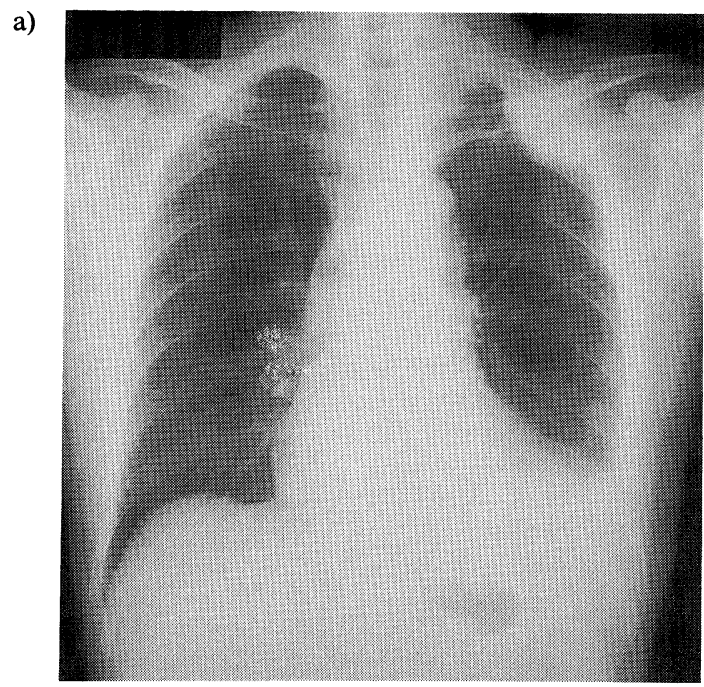

b)
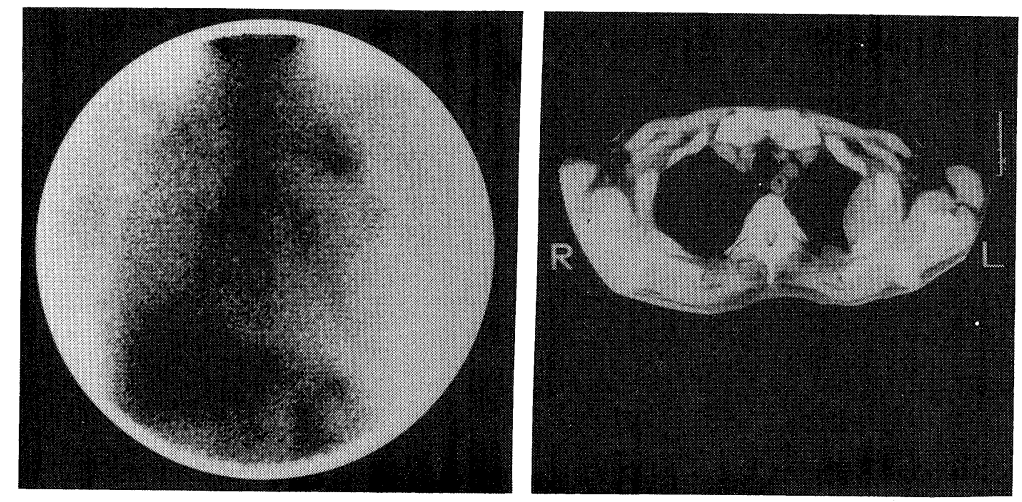

Fig. 5. (a): X-ray film of the chest shows a pleura-based mass and pleural effusion. (b): Left; Anterior view of a Ga-67 scan in a patient with malignant pleural mesothelioma showing localized accumulation in left upper lung field. Right; Thoracic CT showing a pleura-based mass. 

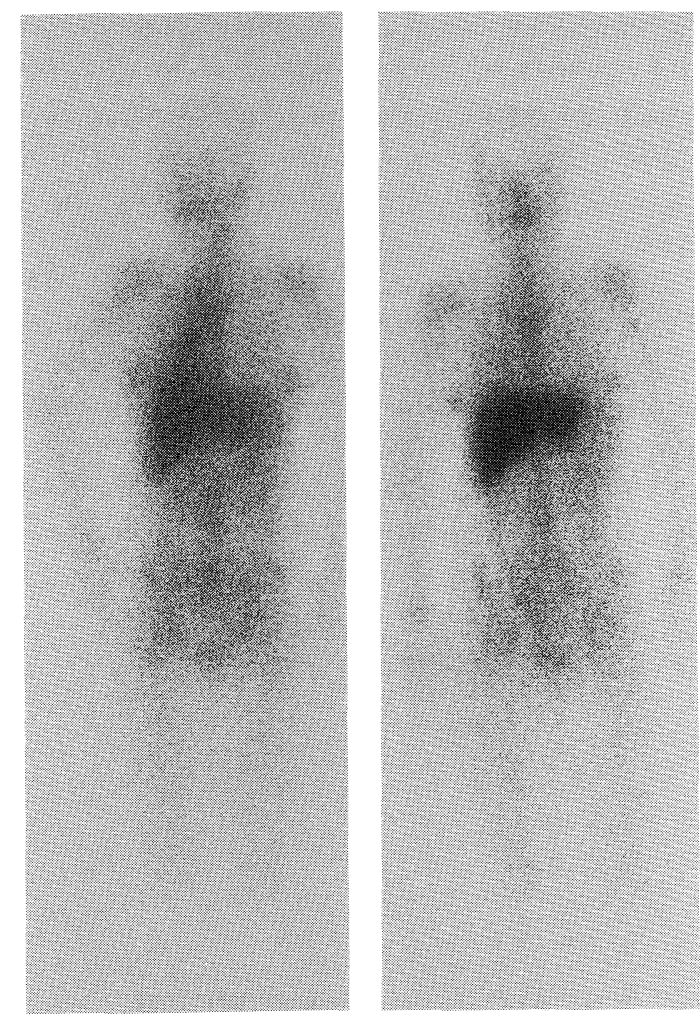

Fig. 6. Left; Anterior view of a Ga-67 scan before chemotherapy showing diffuse strong accumulation over the involved hemithorax. Right; A marked reduction of Ga-67 uptake is shown after combination chemotherapy with cyclophosphamide $1000 \mathrm{mg} / \mathrm{m}^{2}$, vincristine $1 \mathrm{mg} / \mathrm{m}^{2}$, and aclacinomycin $40 \mathrm{mg} / \mathrm{m}^{2}$.

complete agreement with roentgenologic findings. Ga-67 radionuclide imaging is nonspecific. However, these results suggest that a diffusely increased uptake over the entire involved hemithorax is one of the most characteristic findings of Ga-67 scans in malignant pleural mesothelioma. It has been reported that Ga-67 scan is more sensitive than chest radiography in identifying sites of involvement in this neoplasm (12). However, we could not verify any superiority of Ga-67 scanning over chest CT as a means of determining the extent of the disease process.

\section{REFERENCES}

1) Edwards CL, Hayes RL. Tumor scanning with Ga-67 citrate. J Nucl Med 10: 103, 1969.

2) Edwards CL, Hayes RL. Scanning malignant neoplasms with gallium-67. JAMA 212: 1182, 1970.

3) Wolk RB. Gallium-67 scanning in the evaluation of mesothelioma. J Nucl Med 19: 808, 1978.

4) Seo IS, Joo KG, Carter JE. Demonstration of pleural mesothelioma by gallium scan. Clin Nucl Med 5: 407, 1980.

5) McLean RG, Choy D, Murray IPC. Unexpected gallium uptake in benign pulmonary pathology. Report of two cases. Clin Nucl Med 9: 675, 1984.

6) Nakano T, Fujii J, Yamakawa $\mathrm{K}$, et al. Glycosaminoglycan, computed tomography and gallium-67 scanning in malignant pleural mesothelioma. Nippon Kyobu Shikkan Gakkai Zasshi 23: 401, 1985 (in Japanese).

7) Nakano T, Fujii J, Tamura S, et al. Glycosaminoglycan in malignant pleural mesothelioma. Cancer 57: 106, 1986.

8) McCaughey WTE. Primary tumors of the pleura. J Pathol Bacteriol 76: 517, 1958.

9) Bekerman C, Hoffer PB, Bitran JD, et al. Gallium-67 citrate imaging studies of the lung. Semin Nucl Med 3: 286, 1980.

10) Kinoshita F, Ushio T, Maekawa A, Ariwa R, et al. Scintiscanning of pulmonary diseases with Ga-67 citrate. J Nucl Med 15: 227, 1973.

11) Patterson AHG, McReady VR. The current status of gallium-67 scanning. $\mathrm{Br} \mathrm{J}$ Radiol 48: 944, 1975 (Abstract).

12) Sorek M, Rom WN, Goldsmith SJ. Gallium-67 citrate in the staging of diffuse pleural mesothelioma. $\mathrm{J} \mathrm{Nucl}$ Med 19: 692, 1978 (Abstract). 